ritual | eric c. rath

\title{
Mealtime at a \\ Tibetan Monastery
}

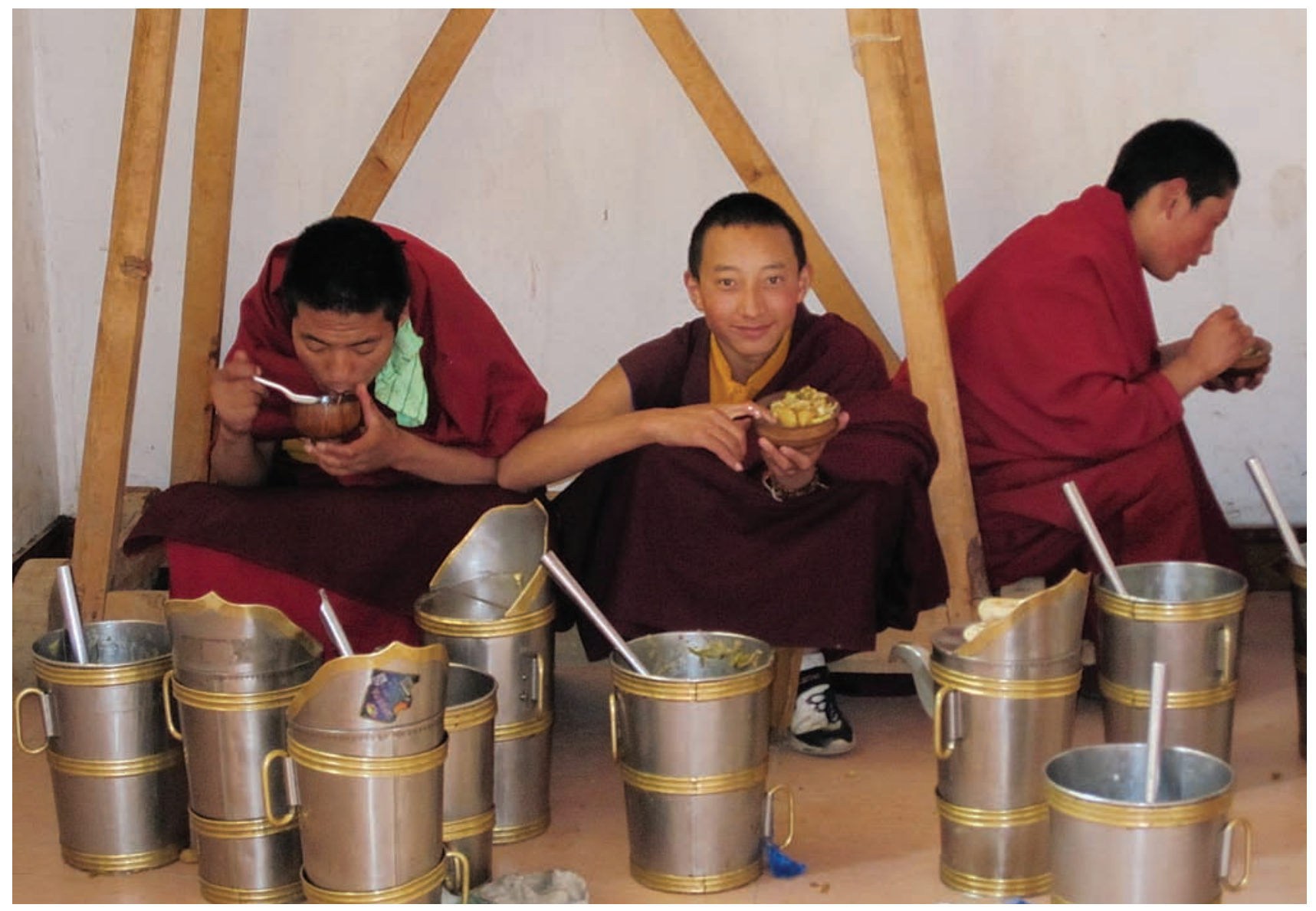

As A GROUP OF YOUNG MONKS trumpet on conch shells, members of Longen Monastery in Qinghai Province, China, assemble in the prayer hall before their midday meal. Monks at Zen monasteries typically walk, bow, and sit with the precision of a synchronized swim team, but here, at the Tibetan Buddhist monastery of Longen, the setting is far more relaxed. Some monks chat, while others clown around. Some hurry; others move at a leisurely pace, adjusting their saffron robes. By the time the horns' last notes have sounded, everyone is settled in place.

At that moment prayers begin at the front of the hall. The well-known vocalizations of Tibetan monks are charac-
Above: Servers enjoy their meal outside the prayer hall. photograph by ERIC C. RATH $@ 2009$

terized by one monk chanting three notes simultaneously. By contrast, the chanting at Longen mimics the sound of a small waterfall, with murmurs arising in independent patterns before merging into a larger, harmonious whole.

Longen Monastery is located in Golok Tibetan Autonomous Prefecture, some nineteen miles from the county seat of Gande. Although remote, Longen maintains sites pivotal to the history of Tibet, including a replica of the country's oldest monastery, Samye, originally built in 


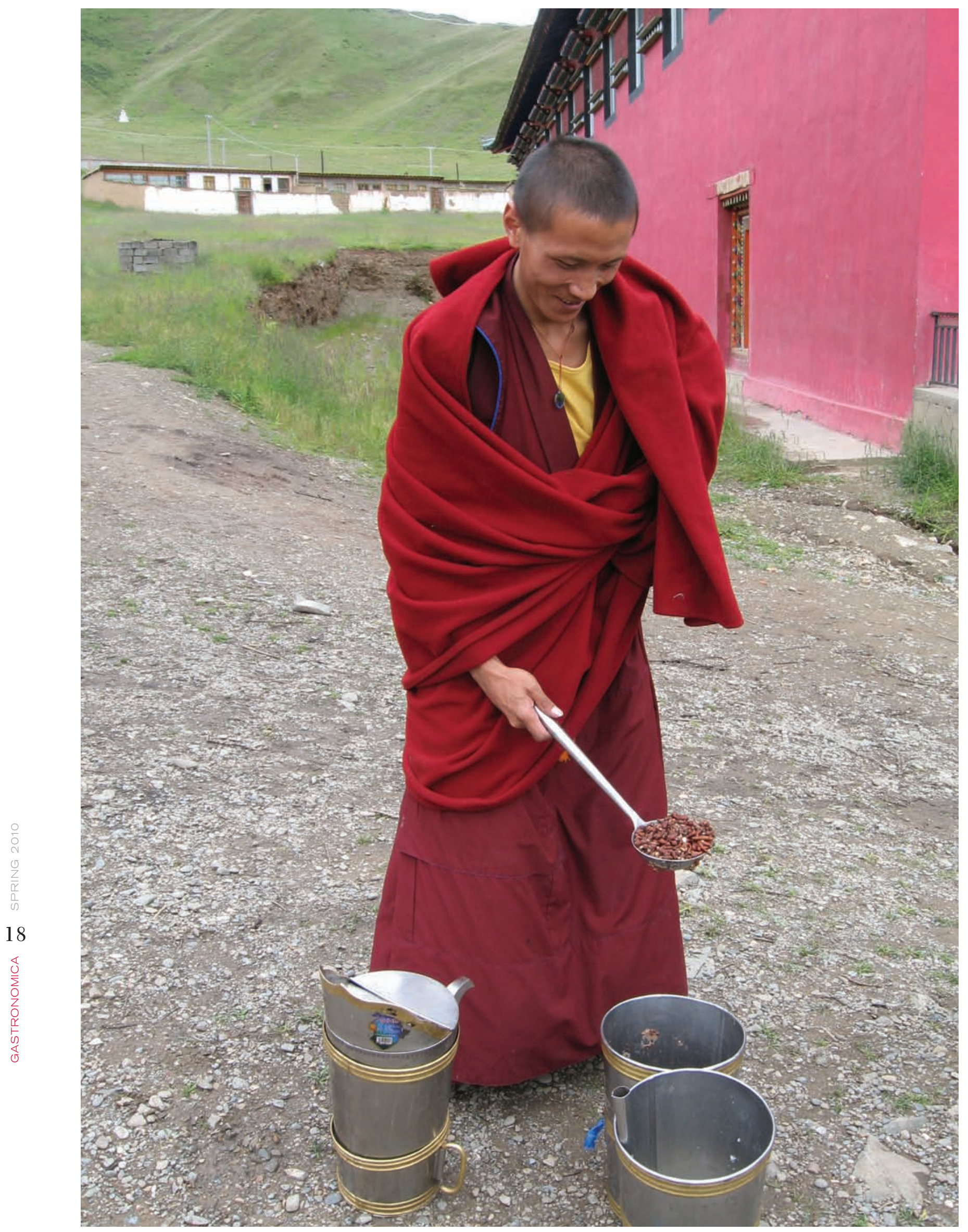




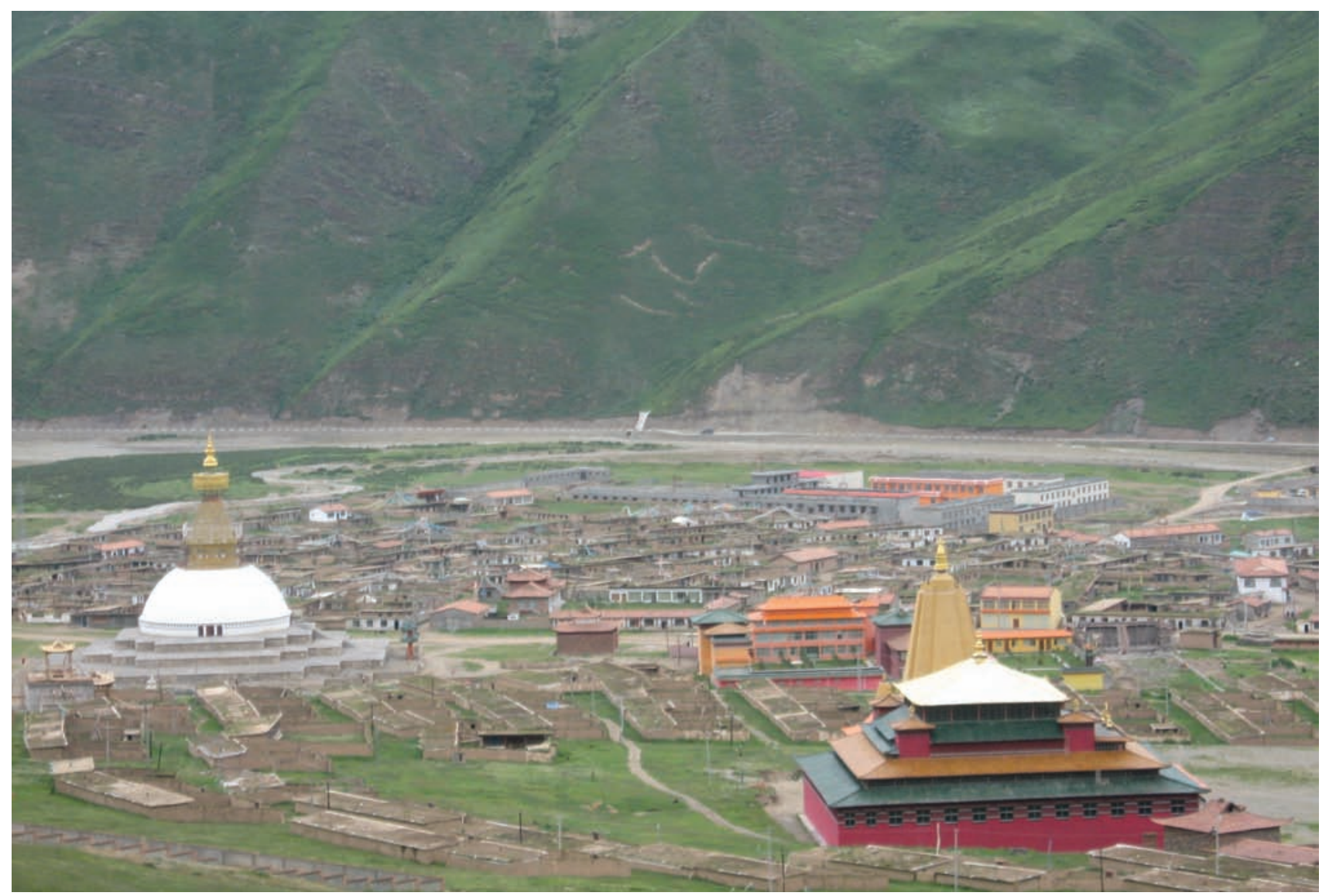

the eighth century A.D. in central Tibet. Along with half a dozen other monuments to Tibetan Buddhist history, Longen reflects the efforts of its former abbot H.H. Kusum Lingpa (who died in 2009) to transmit core elements of Buddhist culture to one of the most remote areas of Tibet.

The monastery's location presents certain logistical problems. At nearly thirteen thousand feet above sea level and with a short growing season, agriculture is impossible. Most ingredients for the monks' meals must be trucked in either from Gande, a forty-minute drive, or from the provincial capital of Xining, eleven hours away. Traditionally this region is home to nomads who raise yak, cows, and sheep. Until several years ago the monks ate that meat, cutting it into large chunks to be boiled on the bone. According to the current abbot, Hungkar Dorje Rinpoche, three hundred monks would consume up to two yaks a day, depending on the animals' weight (each could reach up to 1,300 pounds).

A few years ago, however, the monastery gradually shifted to a vegetarian diet, which is much more in keeping with the ideals of the summer retreat, when the monks remain at the monastery for intensive practice, in part to avoid stepping on and killing insects if they were to travel. By adopting vegetarianism, the monks follow the Buddhist proscription against taking life. However, this shift
Above: Longen Monastery. Left: Monk with a serving of wild sweet potatoes (droma).

PHOTOGRAPHS BY ERIC C. RATH $\bigcirc 2000$

means that they are now almost completely dependent on imported foodstuffs, though yogurt, butter, and milk from dri (female yaks) are still sourced from the nomads.

Longen's buildings include a full-scale replica of the nine-story tower that the Tibetan yogi Milarepa (1040-1123) built in an attempt to satisfy his fickle master, Marpa. There are also Indian stupas marking important moments in the life of Shakyamuni, the historical Buddha. In the midst of these holy monuments stands one rather nondescript brick structure whose importance to monastery life is nonetheless essential. This is the chakang, or kitchen.

In the chakang a staff of a dozen lay volunteers cooks the monks' meals on an enormous concrete stove. Measuring approximately four feet high and fourteen feet wide, and occupying most of the kitchen's interior, this structure looks like a giant's appliance. It is so massive that the cooks must climb steps up to the top of the stove to carry out their work. Equally suggestive of a giant's domain are the cooks' massive wooden stirrers the length of canoe oars, and the five huge, metal caldrons, the zankar. Decorated with auspicious symbols, such as dragons, the 


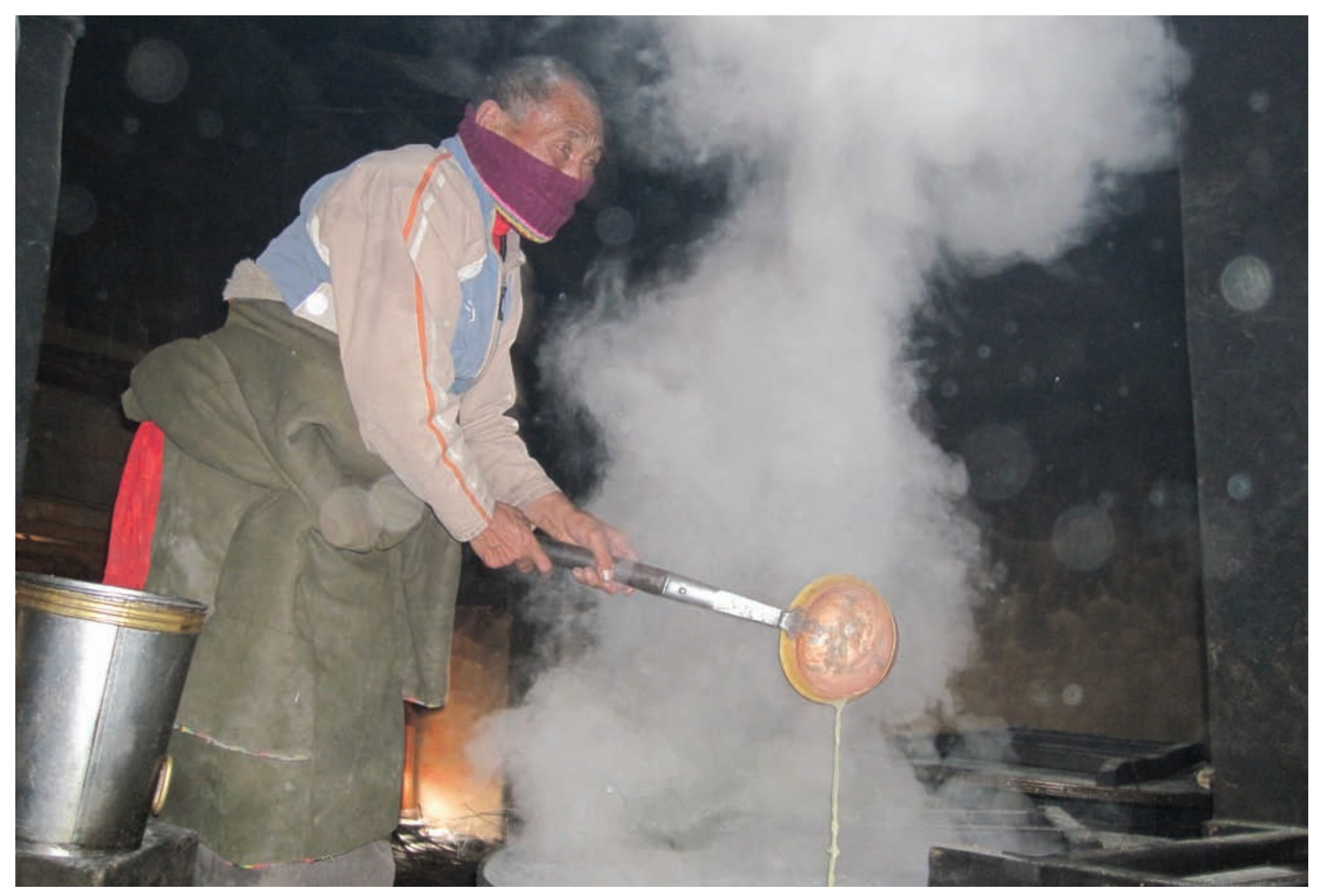

two largest caldrons are three feet in diameter and roughly three feet in depth. All five zankar are built right into the stove, each sitting atop its own fire. Smoke swirls upward and out of the flues in the roof, though not before it has filled the room. Some daylight filters in through the flues, as well as through two windows and around the black curtains that cover two doorways. Visibility is otherwise minimal until the eyes can adjust.

The fires are fueled with wood-a remarkable choice, given that there are practically no trees in the region. Locals usually cook and heat their homes with dried yak dung, but the monks, who do not keep their own livestock, must import wood, as they do their cooking ingredients.

Tea made from milk, tea leaves, and water bubbles in one of the caldrons; potatoes, rice noodles, and vegetables simmer in another. Rice is cooked in a third. Another holds breakfast leftovers: more milk tea and boiled droma, the wild, deep-red sweet potatoes harvested in spring and autumn when they are pencil-thin and about the length of a child's finger. For festive occasions rice is topped with these droma, then melted butter and yogurt are ladled over it. Then a tablespoon of refined sugar is sprinkled over the top.

When the monks enter the hall for prayers, they sit down on cushions on long, raised platforms running the
Above: A kitchen volunteer stands on the stove to stir tea. Right: A monk serves bread in the prayer hall.

photographS bY ERIC C. RATH 20009

length of the temple's center. A shelf-like table is attached at each place, under which the monks store their books or other belongings. Three small, circular loaves of bread are already in place on each table when the monks file in. After the monks have finished praying, young monk-servers carry in the warm food, filling two bowls for each monk, one with rice, the other with the dish of the day. The servers make their way along the aisles, then return with second portions, as well as with tea, which is poured into one of the now-empty bowls.

The midday meal at Longen Monastery is less a religious ceremony than a social gathering, a moment of commensality when the monks can share a leisurely meal. Only the servers are left out of this gathering. When their duties are done, they sit down to eat leftovers in the hall outside. $\odot$

NOTE

Thanks to Hungkar Dorje Rinpoche for allowing my visit and Eric Conrad for his help. 


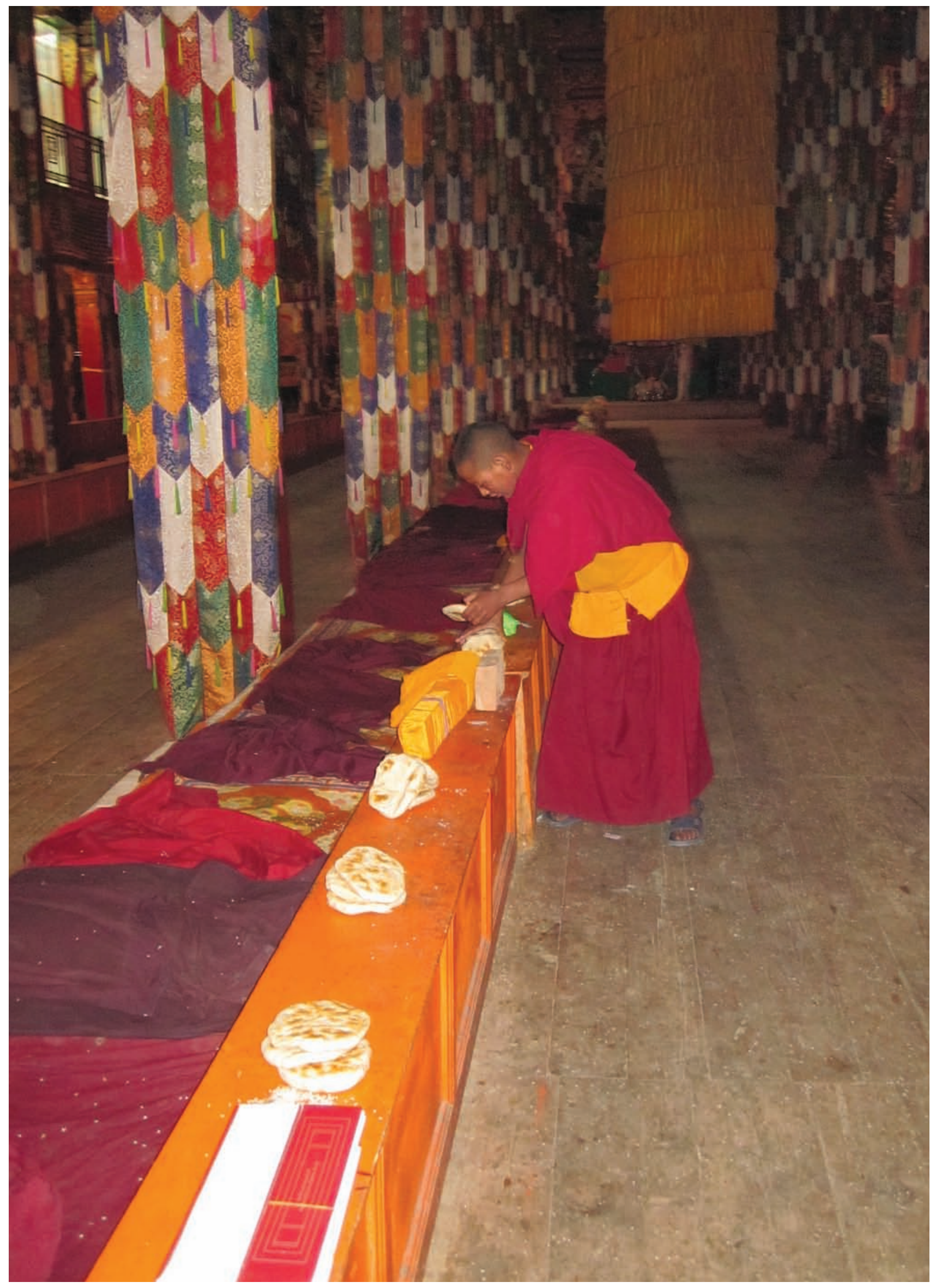

